\title{
Current and emerging treatment strategies for breast cancer-induced bone loss
}

This article was published in the following Dove Press journal:

Breast Cancer:Targets and Therapy

26 October 2010

Number of times this article has been viewed

\section{Stephanie L Hines}

Department of Internal Medicine, Multidisciplinary Breast Clinic, Mayo Clinic Florida, Jacksonville, FL, USA
Correspondence: Stephanie L Hines Department of Internal Medicine, Multidisciplinary Breast Clinic, Mayo Clinic Florida, 4500 San Pablo Rd, Jacksonville, FL 32224, USA

Tel + I 9049530707

Fax + I 904953 |4I2

Email hines.stephanie@mayo.edu
Abstract: Breast cancer increases a woman's risk for bone loss. Bone loss occurs due to the skeletal fragility associated with malignancy, the occurrence of premature ovarian failure secondary to chemotherapy, and the loss of bone mineral density (BMD) associated with antiestrogen therapies. Tamoxifen has been shown to reduce BMD among premenopausal women, and aromatase inhibitors, which have become a standard therapy among postmenopausal women, increase bone loss and the risk of fracture. Bisphosphonates preserve BMD among women with breast cancer, both among postmenopausal women and those with a history of significant bone loss. The effect among premenopausal women appears modest. Despite the protective effect on bone density, a reduction in the risk of fracture has not yet been established. Therefore, other risk factors for fracture must be addressed, such as dietary intake, vitamin D, and assessment of other potentially modifiable conditions. Newer agents that target the receptor activator of nuclear factor- $\kappa$ B (RANK) system and RANK ligand (RANKL), such as denosumab, represent an emerging class of medications that may also preserve BMD in this population.

Keywords: breast cancer, bone mineral density, fracture, bisphosphonates, cancer therapy-induced bone loss

\section{Introduction}

Breast cancer is the most common malignancy among women in the United States, with an estimated 207,090 women expected to be diagnosed in $2010 .{ }^{1}$ With less than 40,000 women expected to die because of the disease this year, increasingly more women will survive and require ongoing medical care. Care of the women with breast cancer requires knowledge of a variety of specific medical issues that confront these patients, such as the increased risk for bone loss and fracture.

Breast cancer increases the risk of a woman for bone loss. Bone loss occurs through multiple mechanisms, including the risk of premature ovarian failure, the increased risk of bone loss following the onset of menopause, and the effect of cancer therapies on bone mineral density (BMD). These women are also commonly advised to avoid the use of estrogen therapy, which has previously been considered the first-line therapy for the prevention of osteoporosis, as the majority of breast cancers are defined by the presence of estrogen and/or progesterone receptors. This leaves limited options for the treatment of breast cancer therapy-induced bone loss. In addition to the recently identified receptor activator of nuclear factor- $\kappa \mathrm{B}$ ligand (RANKL) inhibitors such as denosumab, which inhibit osteoclast stimulation, the effects of nonhormonal options such as the bisphosphonates, which inhibit osteoclast-mediated bone resorption, have been investigated in this setting. This review investigates the current and emerging 
treatment strategies using these nonhormonal agents for patients with known cancer-induced bone loss.

\section{Breast cancer-induced bone loss}

Women with localized or early-stage breast cancer undergoing adjuvant chemotherapy are at increased risk for bone loss. Those with the most significant loss of bone density are the ones who experience premature ovarian failure. ${ }^{2-4}$ The rate of chemotherapy-related amenorrhea is most affected by the choice of chemotherapeutic agent, dosing, and the age of the patient at treatment, with those over 40 at highest risk. ${ }^{5-7}$ Menopause in these women may occur up to 10 years early, ${ }^{2}$ and those women who become menopausal are documented to have a BMD significantly lower than women who remain premenopausal after treatment, ${ }^{3,4}$ with a documented difference in BMD at 1 year of between $3 \%-14 \%$ at the lumbar spine.

Women are also at risk of bone loss from antihormonal therapy. Tamoxifen, a selective estrogen receptor modulator, has been used primarily for hormone-sensitive breast cancers for over 20 years. Although tamoxifen has been shown to increase BMD in postmenopausal women, BMD declines by $1.44 \%$ per year among premenopausal women compared with a $0.24 \%$ increase among women taking placebo. ${ }^{8}$ Despite the protective effect on BMD in postmenopausal women, tamoxifen is not used commonly in this population. Aromatase inhibitors (AIs) such as letrozole, anastrozole, and exemestane are now considered for first-line therapy, either as primary adjuvant treatment or in sequence following tamoxifen after several studies documented a significant improvement in disease-free survival when compared with tamoxifen alone. ${ }^{9-16}$

AIs prevent the peripheral conversion of androgens into estrogens. Although this effect improves the risk of recurrence in women with breast cancer, it also has a detrimental effect on bone. AIs have been documented to increase the risk of fracture $^{9,10,13-17}$ and osteoporosis. Bone loss of 4\%-5\% at the lumbar spine has been documented after 2 years of AI therapy, ${ }^{18,19}$ with between $3 \%$ and $4 \%$ loss at the hip. From baseline to 5 years, therapy with anastrozole was associated with an $8.1 \%$ lower BMD at the lumbar spine than tamoxifen ${ }^{20}$ among postmenopausal women participating in the Anastrozole Tamoxifen Alone or in Combination trial.

In addition, breast cancer itself, without the presence of skeletal metastases, may affect the risk of fracture. Women with newly diagnosed breast cancer without the presence of soft tissue or skeletal metastases have been documented to have an almost five-fold increase in the risk of vertebral fractures compared with healthy women. ${ }^{21}$ Those with soft tissue metastases and without known skeletal metastases have a 23-fold increased risk of vertebral fracture. These fracture rates remain significantly elevated even after those subsequently found to have skeletal disease are excluded. This effect may be mediated through the presence of a parathyroid-related peptide, often associated with the presence of malignancy, through chemotherapy, or possibly through the effect of premature ovarian failure.

\section{Bisphosphonates}

Bisphosphonates, a class of drug approved by the US Food and Drug Administration (FDA) for the treatment of postmenopausal osteoporosis, bind to bone and inhibit osteoclastmediated bone resorption. Available pharmacologic options in the United States include alendronate, risedronate, ibandronate, and zoledronic acid. Zoledronic acid has also been approved for the treatment of metastatic bone disease in women with advanced breast cancer. A variety of bisphosphonates have also been evaluated for their effects on breast cancer therapy-induced bone loss.

\section{Postmenopausal breast cancer patients}

Postmenopausal women on AIs are at particularly increased risk of bone loss. Several studies have examined the role of bisphosphonates in this setting and are outlined in Table 1. One of the most extensively studied agents in this population is intravenous zoledronic acid at doses of $4 \mathrm{mg}$ every 6 months for 5 years. ${ }^{22,23}$ Two studies reported the effect of zoledronic acid on postmenopausal women (with a $T$ score $>-2.0$ ) initiating letrozole following tamoxifen. When initiated concurrently with the letrozole, zoledronic acid improved BMD at the lumbar spine by $4.4 \%$ and $5.3 \%$ at 1 year compared with those on letrozole alone. A similar effect was also noted at the total hip and femoral neck regions in these patients. Despite these benefits, a significant reduction in the risk of fracture has not been documented.

Others examined the effect of ibandronate $150 \mathrm{mg}$ monthly in addition to anastrozole $1 \mathrm{mg}$ daily on the BMD in postmenopausal breast cancer patients with documented osteopenia and $T$ score of -1.0 to $-2.5 .^{24}$ After 2 years of therapy with anastrozole and ibandronate, the BMD at the lumbar spine was $2.98 \%$ higher than the baseline, whereas those on anastrozole alone experienced a $3.22 \%$ loss at the same site. A similar effect was noted at the hip. Over the course of 2 years, six patients on ibandronate recovered normal bone density with only one developing osteoporosis. 


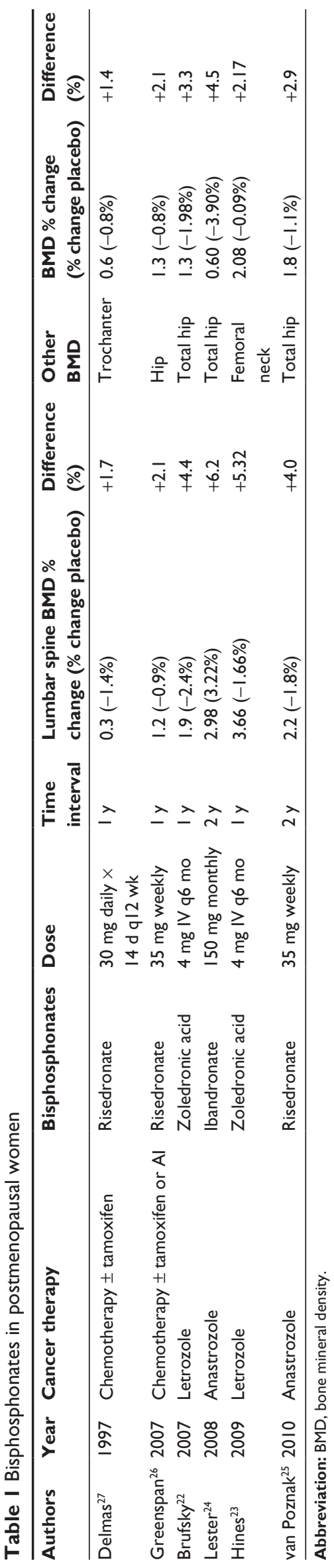

No patients on anastrozole alone recovered normal bone density, with five developing osteoporosis.

Risedronate has also been reported to improve BMD among postmenopausal breast cancer patients on AIs. ${ }^{25}$ Its effect was examined in the study of anastrozole with the bisphosphonate risedronate (SABRE) using three populations of postmenopausal women on adjuvant therapy with anastrozole. Among women with normal bone density, a $T$ score $\geq-1.0$, and taking anastrozole $1 \mathrm{mg}$ daily alone, the lumbar spine BMD declined by $2.1 \%$ at 2 years. However, women with a moderate fracture risk ( $T$ score $<-1.0$ but $\geq-2.0$ ) randomized to risedronate $35 \mathrm{mg}$ weekly and anastrozole $1 \mathrm{mg}$ daily experienced a $2.2 \%$ increase in lumbar spine BMD, whereas those on anastrozole alone lost $1.8 \%$ during this interval.

The effect of risedronate has also been studied on two smaller groups of women who became prematurely menopausal following chemotherapy. BMD was $2.1 \%$ greater at the lumbar spine and hip at 1 year among patients randomized to risedronate $35 \mathrm{mg}$ weekly compared with placebo. ${ }^{26}$ Following 2 years of therapy in the second trial, lumbar spine BMD was $2.5 \%$ greater among women randomized to risedronate than placebo, with a $2.6 \%$ greater BMD at the femoral neck. ${ }^{27}$

These data consistently demonstrate the protective effect of bisphophonates on BMD among postmenopausal women with breast cancer on AIs (and normal to moderate fracture risk) and suggest that these patients may benefit from the concurrent therapy. Concurrent therapy prevents the expected decline of BMD in this population although a significant effect on fracture risk has not yet been determined.

\section{Postmenopausal osteoporosis or osteopenia at increased fracture risk}

The increased fracture risk and bone loss associated with AIs may pose a potentially significant deterrent to clinicians in their selection of adjuvant hormonal therapy. Women with a history of osteoporosis (defined by a $T$ score $\leq-2.5$ or a BMD at least 2.5 standard deviations below that of the mean BMD of a young adult) or significant osteopenia ( $T$ score $<-2.0$ ) are already considered to be at increased fracture risk, a risk that would be further enhanced by the use of AIs. Whether bisphosphonates also improve BMD among women starting an AI with significant preexisting bone loss remains a clinical concern.

Studies have documented a similarly protective effect of bisphosphonates in this population (Table 2). Intravenous zoledronic acid at a dosage of $4 \mathrm{mg}$ for every 6 months improved $\mathrm{BMD}$ at the lumbar spine by $2.66 \%$ at 1 year among women with 
Table 2 Bisphosphonates in postmenopausal women with osteoporosis or significant osteopenia ( $T$ score $\leq 2.0)$

\begin{tabular}{|c|c|c|c|c|c|c|c|c|}
\hline Authors & Year & Cancer therapy & Bisphosphonates & Dose & $\begin{array}{l}\text { Time } \\
\text { interval }\end{array}$ & $\begin{array}{l}\text { Lumbar spine } \\
\text { BMD \% change }\end{array}$ & Other BMD & BMD \% change \\
\hline Lester $^{24}$ & 2008 & Anastrozole & Ibandronate & $\begin{array}{l}150 \mathrm{mg} \\
\text { monthly }\end{array}$ & $2 y$ & +3.52 & Total hip & +2.49 \\
\hline Hines $^{23}$ & 2009 & Letrozole & Zoledronic acid & $\begin{array}{l}4 \mathrm{mg} \mathrm{IV} \\
\text { q6 mo }\end{array}$ & Iy & +2.66 & Femoral neck & +4.81 \\
\hline van Poznak ${ }^{25}$ & 2010 & Anastrozole & Risedronate & $\begin{array}{l}35 \mathrm{mg} \\
\text { weekly }\end{array}$ & $2 y$ & +3.0 & Total hip & +2.0 \\
\hline
\end{tabular}

Abbreviation: BMD, bone mineral density.

a $T$ score $\leq-2.0$ taking letrozole $2.5 \mathrm{mg}$ daily. BMD measured at the femoral neck improved by $4.81 \%$ during this interval as well. ${ }^{28}$ Women at high fracture risk $(T$ score $<-2.0)$ assigned to anastrozole $1 \mathrm{mg}$ daily and risedronate $35 \mathrm{mg}$ weekly in the SABRE trial also experienced a 3\% improvement in lumbar spine BMD and $2 \%$ improvement at the hip over 2 years. ${ }^{25}$ After 2 years, monthly therapy with ibandronate $150 \mathrm{mg}$ improved the lumbar spine BMD of osteoporotic patients taking anastrozole by $3.52 \%$ and the total hip BMD by $2.49 \%{ }^{24}$

\section{Premenopausal breast cancer patients}

The effect of bisphosphonates on the documented bone loss occurring in premenopausal women has also been examined (Table 3). Studies in this population included risedronate, zoledronic acid, and clodronate; the results are variable. Risedronate was tested in premenopausal women undergoing adjuvant chemotherapy for early-stage breast cancer. ${ }^{29}$ Concurrent with chemotherapy, women were randomized to risedronate $35 \mathrm{mg}$ weekly or placebo. Although those on placebo lost $5.4 \%$ BMD at the lumbar spine at 1 year, those on risedronate unexpectedly lost $4.3 \%$. Similar effects were also noted at the total hip and femoral neck regions. Although these results are not considered significant, those on risedronate experienced less bone loss than those on placebo, suggesting a mild effect that may not have been detected given the higher than expected level of patient dropout (170 of 216 patients completing the 1-year study). Risedronate also demonstrated a slightly less robust effect on BMD among postmenopausal women than zoledronic acid, suggesting that a more potent bisphosphonate may have a greater influence on premenopausal BMD.

Studies with clodronate 1,600 mg daily demonstrated a modest effect on preserving BMD among premenopausal women undergoing adjuvant chemotherapy, ${ }^{30,31}$ with an overall $2 \%-4 \%$ difference in lumbar spine BMD between patients taking clodronate and placebo over 2 years. In one of these studies, clodronate provided greater protection from bone loss among those women who developed premature ovarian failure secondary to chemotherapy, whereas those who developed premature ovarian failure and took placebo experienced the greatest amount of bone loss. Women who retained menstrual function had a marginal decline in BMD and, thus, experienced a more limited effect from the clodronate. ${ }^{30}$ The second study documented a more significant bone loss among those women who remained premenopausal, possibly due to the detrimental effect of tamoxifen in this population. At 2 years, premenopausal women experienced an approximately $4 \%$ loss of lumbar spine BMD regardless of treatment with clodronate or placebo. Those women who developed ovarian failure in this study experienced a mild increase in their lumbar spine BMD, thought to be secondary to the beneficial effect of tamoxifen in this population. However, those on clodronate experienced greater gains in BMD than those on placebo. ${ }^{31}$

Premenopausal women may also undergo adjuvant hormonal therapy with ovarian function suppression. The effect of zoledronic acid on premenopausal women undergoing ovarian suppressive therapy with goserelin, a luteinizing hormone-releasing hormone (LHRH) analog, and then randomly treated with tamoxifen or anastrozole daily was evaluated. ${ }^{32}$ Although premenopausal at study onset, treatment with a LHRH analog such as goserelin makes these women functionally postmenopausal. Therefore, those treated with goserelin and anastrozole lost $17.4 \%$ of bone density at the lumbar spine over 3 years, with an $11.6 \%$ decline for those taking goserelin and tamoxifen. All patients on zoledronic acid maintained stable bone densities over 3 years of treatment, regardless of their assignment to tamoxifen or anastrozole.

\section{Emerging options}

Emerging options for the management of breast cancer-induced bone loss may include the RANKL inhibitors. The RANK is expressed on a variety of cells, including osteoclasts and osteoclast precursors. The activation of these receptors by RANKL is vital to osteoclast formation and function. Inhibition of the RANKL by osteoprotegerin, a naturally occurring protein, impairs osteoclast-mediated bone resorption. 


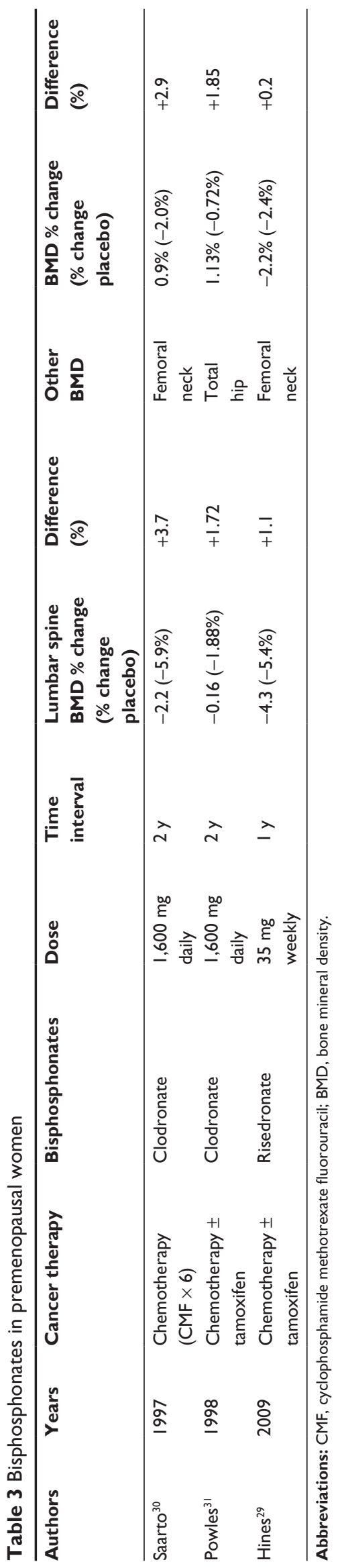

The development of RANKL inhibitors impairs RANK activation by blocking the stimulatory ligand. ${ }^{33,34}$

Denosumab is a fully human monoclonal antibody to RANKL. It was first found to be effective in the treatment of postmenopausal women with low BMD. After 12 months of subcutaneous therapy the BMD at the lumbar spine improved by $3.0 \%-6.7 \%$ and total hip improved by $1.9 \%-3.6 \%$. These improvements were comparable to the effect of oral alendronate at the lumbar spine and total hip at 12 months and better than the treatment with placebo. ${ }^{34}$ Others have documented a reduction in serum and urine markers of bone resorption following treatment with denosumab among patients with metastatic bone disease secondary to multiple myeloma, breast cancer, and other malignancies, ${ }^{35-37}$ suggesting a possible role for denosumab in the treatment of skeletal metastases.

Women with early-stage breast cancer may also benefit from this agent. The effect of subcutaneous denosumab $60 \mathrm{mg}$ for every 6 months was reported in women with osteopenia and early stage hormone receptor-positive breast cancer undergoing adjuvant therapy with an $\mathrm{AI} .{ }^{38}$ Denosumab increased lumbar spine BMD by $5.5 \%$ at 12 months and $7.6 \%$ at 24 months compared with placebo, with a $4.7 \%$ and $6.1 \%$ improvement at the total hip and femoral neck, respectively, at 24 months. Although patients were stratified by the duration of AI therapy, no effect of the duration of AI exposure was noted. No vertebral fractures were reported, and a similar number of nonvertebral fractures occurred in both groups.

These results suggest that inhibition of the RANK system and RANKL may offer additional options for treatment of cancer therapy-induced bone loss in the future. Denosumab appears well tolerated with a similar adverse effect profile to placebo ${ }^{38}$ and may someday receive FDA approval for this indication. This development also increases the opportunity for investigation of the RANK system for other mechanisms to prevent osteoclast-mediated bone resorption.

\section{Conclusion}

Women with breast cancer are at increased risk for both bone loss and fracture. Much of this increase in risk is mediated by the presence of malignancy-induced skeletal fragility ${ }^{21}$ or cancer therapy-induced bone loss. A majority of these cancers have hormone receptors that make them responsive to the presence of estrogen or progesterone. Thus, patients with breast cancer are commonly advised against known bone-protective therapies such as hormonal therapy.

Nonhormonal options for protection of bone density have been investigated and are promising. These include a variety of bisphosphonates and RANKL inhibitors such as denosumab. 
Clinicians now have medical evidence to guide treatment decisions in the management of bone loss. Among the bisphosphonates studied, zoledronic acid has the most potent effect on the preservation of BMD in postmenopausal women and would be an ideal option for those with significant preexisting bone loss. It also offers the convenience of infrequent dosing on a 6-month schedule, which may be suitable for patients who may be limited by travel restrictions. Zoledronic acid is administered intravenously and bypasses the oral route that is most commonly associated with adverse gastrointestinal effects although its use may be limited by cost and patient access to a facility that can provide infusion therapy. Both risedronate $35 \mathrm{mg}$ weekly and ibandronate $150 \mathrm{mg}$ monthly also stabilize BMD in this population when used concurrently with AIs and are readily available as oral alternatives.

Current options for premenopausal women are limited by the available literature. Bisphosphonates have shown a modest effect among premenopausal women, which may be related to the lack of significant bone decline in those who retain menstrual function following chemotherapy. ${ }^{30}$ Others have shown a larger than expected patient dropout during the concurrent administration of bisphosphonates with chemotherapy, possibly due to the cumulative toxicity of the two regimens, suggesting that symptomatology of patients may limit compliance. ${ }^{29}$ Clinicians may, therefore, reasonably consider ongoing surveillance of BMD during active chemotherapy with the option of later adding bisphosphonate therapy during the course of antiestrogen therapy. In this scenario, tamoxifen would increase bone loss among those who remain premenopausal, AIs would increase bone loss among those who become menopausal, and bisphosphonates would preserve BMD in both groups of patients. In those premenopausal women with significant bone density concerns who may tolerate the addition of a bisphosphonate or who are considered at elevated risk for fracture, risedronate and clodronate demonstrated a minor effect (although this latter agent is not approved by the FDA in the United States).

Women who undergo ovarian suppression therapy with an LHRH analog become functionally postmenopausal, and the risk of bone loss is compounded by the addition of AIs such as anastrozole. Although this combination has been shown to decrease lumbar spine BMD by over $17 \%$ over 3 years, ${ }^{32}$ the concurrent administration of zoledronic acid counteracts this decline and stabilizes bone.

Despite the stabilizing effect of bisphosphonates on BMD among breast cancer patients, they have not yet been shown to reduce the risk of fracture. A multitude of other factors affect the risk of fracture, including the age of a patient, the presence of comorbidities that may affect gait (such as peripheral neuropathy or other neurologic conditions), vision, medication therapies, nutrition and gastrointestinal absorption of nutrients, and bone mineralization disorders such as osteomalacia. Therefore, the degree to which changes in BMD affect fracture risk may be difficult to predict. The correlation between changes in BMD and fracture risk has been examined in an analysis of three trials of risedronate therapy in postmenopausal women with osteoporosis. Although the risk of fracture increases with declines in BMD, a decrease in fracture rates occurred among all patients who gained BMD. No significant difference in fracture rates could be detected between those who gained more or less than 5\% BMD from baseline. ${ }^{39}$ Therefore, a larger increase in BMD does not imply a larger reduction in fracture risk, and thus other factors must be considered. The identification of potentially modifiable factors should also be incorporated into the treatment plan, with attention to dietary intake, calcium, vitamin $\mathrm{D}$, weight-bearing exercise, medications, and other conditions that may modify fracture risk. Additional pharmacologic agents such as denosumab and other potential RANK system inhibitors may provide future options for bone preservation.

\section{Disclosure}

The author reports no conflicts of interest in this work.

\section{References}

1. American Cancer Society. Cancer Facts and Figures 2010. Atlanta, GA: American Cancer Society; 2010.

2. Bruning PF, Pit MJ, de Jong-Bakker M, van den Ende A, Hart A, van Enk A. Bone mineral density after adjuvant chemotherapy for premenopausal breast cancer. Br J Cancer. 1990;61(2):308-310.

3. Shapiro CL, Manola J, Leboff M. Ovarian failure after adjuvant chemotherapy is associated with rapid bone loss in women with early-stage breast cancer. J Clin Oncol. 2001;19(14):3306-3311.

4. Headley JA, Theriault RL, LeBland AD, Vassilopoulou-Sellin R, Hortobagyi GN. Pilot study of bone mineral density in breast cancer patients treated with adjuvant chemotherapy. Cancer Investig. 1998;16(1):6-11.

5. Partridge AH, Burstein HJ, Winer EP. Side effects of chemotherapy and combined chemohormonal therapy in women with early-stage breast cancer. J Natl Cancer Inst Monogr. 2001;30:135-142.

6. Goodwin PJ, Ennis M, Pritchard KI, Trudeau M, Hood N. Risk of menopause during the first year after breast cancer diagnosis. J Clin Oncol. 1999;17(8):2365-2370.

7. Bines J, Oleske DM, Cobleigh MA. Ovarian function in premenopausal women treated with adjuvant chemotherapy for breast cancer. J Clin Oncol. 1996;14(5):1718-1729.

8. Powles TJ, Hickish T, Kanis JA, Tidy A, Ashley S. Effect of tamoxifen on bone mineral density measured by dual-energy $\mathrm{x}$-ray absorptiometry in healthy premenopausal and postmenopausal women. J Clin Oncol. 1996;14(1):78-84.

9. Jakesz R, Jonat W, Gnant M, et al. Switching of postmenopausal women with endocrine-responsive early breast cancer to anastrozole after 2 years' adjuvant tamoxifen: combined results of ABCSG trial 8 and ARNO 95 trial. Lancet. 2005;366:455-462.

10. Coombes RC, Hall E, Gibson LJ, et al. A randomized trial of exemestane after two to three years of tamoxifen therapy in postmenopausal women primary breast cancer. $N$ Engl J Med. 2004;350(11):1081-1092. 
11. Coates AS, Keshaviah A, Thürlimann B, et al. Five years of letrozole compared with tamoxifen as initial adjuvant therapy for postmenopausal women with endocrine-responsive early breast cancer: update of study BIG 1-98. J Clin Oncol. 2007;25(5):486-492.

12. Thürlimann B, Keshaviah A, Coates AS, et al; for Breast International Group (BIG) 1-98 Collaborative Group. A comparison of letrozole and tamoxifen in postmenopausal women with early breast cancer. $N$ Engl J Med. 2005;353(26):2747-2757.

13. Goss PE, Ingle JN, Martino S, et al. A randomized trial of letrozole in postmenopausal women after five years of tamoxifen therapy for early-stage breast cancer. N Engl J Med. 2003;349(19):1793-1802.

14. Baum M, Budzar AU, Cuzick J, et al; for The Arimidex, Tamoxifen, Alone or in Combination Trialists' Group. Anastrozole alone or in combination with tamoxifen versus tamoxifen alone for adjuvant treatment of postmenopausal women with early breast cancer: first results of the ATAC randomized trial. Lancet. 2002;359:2131-2139.

15. Baum M, Budzar AU, Cuzick J, et al; for The Arimidex, Tamoxifen, Alone or in Combination Trialists' Group. Anastrozole alone or in combination with tamoxifen versus tamoxifen alone for adjuvant treatment of postmenopausal women with early breast cancer: results of the ATAC trial efficacy and safety update analyses. Cancer. 2003;98(9):1802-1810.

16. Forbes JF, Cuzick J, Buzdar A, Howell A, Tobias JS, Baum M; for The Arimidex, Tamoxifen, Alone or in Combination Trialists' Group. Effect of anastrozole and tamoxifen as adjuvant treatment for early-stage breast cancer: 100-month analysis of the ATAC trial. Lancet Oncol. 2008;9:45-53.

17. Coleman RE, Banks LM, Girgis SI, et al. Skeletal effects of exemestane on bone-mineral density, bone biomarkers, and fracture incidence in postmenopausal women with early breast cancer participating in the Intergroup Exemestane Study (IES): a randomized controlled study. Lancet Oncol. 2007;8:119-127.

18. Perez EA, Josse RG, Pritchard KI, et al. Effect of letrozole versus placebo on bone mineral density in women with primary breast cancer completing 5 or more years of adjuvant tamoxifen: a companion study to NCIC CTG MA.17. J Clin Oncol. 2006;24(22):3629-3635.

19. Eastell R, Hannon RA, Cuzick J, Dowsett M, Clack G, Adams JE. Effect of an aromatase inhibitor on BMD and bone turnover markers: 2-year results of the Anastrozole, Tamoxifen, Alone or in Combination (ATAC) trial. J Bone Miner Res. 2006;21:1215-1223.

20. Coleman RE; for ATAC Trialists' Group. Effect of anastrozole on bone mineral density: 5-year results from the "Arimidex", Tamoxifen, Alone or in combination (ATAC) trial. J Clin Oncol. 2006;24(18S):511.

21. Kanis JA, McCloskey EV, Powles T, Paterson AHG, Ashley S, Spector T. A high incidence of vertebral fracture in women with breast cancer. Br J Cancer. 1999;79(7/8):1179-1181.

22. Brufsky A, Harker WG, Beck JT, et al. Zoledronic acid inhibits adjuvant letrozole-induced bone loss in postmenopausal women with early breast cancer. J Clin Oncol. 2007;25(7):829-836.

23. Hines SL, Mincey B, Dentchev T, et al. Immediate versus delayed zoledronic acid for prevention of bone loss in postmenopausal women with breast cancer starting letrozole after tamoxifen-N03CC. Breast Cancer Res Treat. 2009; 117:603-609.

24. Lester JE, Dodwell D, Purohit OP, et al. Prevention of anastrozoleinduced bone loss with monthly oral ibandronate during adjuvant aromatase inhibitor therapy for breast cancer. Clin Cancer Res. 2008;14(19):6336-6342.
25. van Poznak C, Hannon RA, Mackey JR, et al. Prevention of aromatase inhibitor-induced bone loss using risedronate: the SABRE trial. J Clin Oncol. 2010;28(6):967-975.

26. Greenspan SL, Bhattacharya RK, Sereika SM, Brufsky A, Vogel VG. Prevetnion of bone loss in survivors of breast cancer: a randomized double-blind, placebo-controlled clinical trial. J Clin Endocrinol Metab. 2007;92:131-136.

27. Delmas PD, Balena R, Confravreux E, Hardouin C, Hardy P, Bremond A. Bisphosphonate risedronate prevents bone loss in women with artificial menopause due to chemotherapy of breast cancer: a double-blind, placebo-controlled study. J Clin Oncol. 1997;15(3):955-962.

28. Hines SL, Sloan JA, Atherton PJ, et al. Zoledronic acid for treatment of osteopenia and osteoporosis in women with primary breast cancer undergoing adjuvant aromatase inhibitor therapy. Breast. 2010;19:92-96.

29. Hines SL, Mincey BA, Sloan JA, et al. Phase III randomized, placebocontrolled, double-blind trial of risedronate for the prevention of bone loss in premenopausal women undergoing chemotherapy for primary breast cancer. J Clin Oncol. 2009;27(7):1047-1053.

30. Saarto T, Blomqvist C, Välimäki M, Päkelä P, Sarna S, Elomaa I. Chemical castration induced by adjuvant cyclophosphamide, methotrexate, and fluorouracil chemotherapy causes rapid bone loss that is reduced by clodronate: a randomized study in premenopausal breast cancer patients. J Clin Oncol. 1997;15(4):1341-1347.

31. Powles TJ, McCloskey E, Paterson AHG, et al. Oral clodronate and reduction in loss of bone mineral density in women with operable primary breast cancer. J Natl Cancer Inst. 1998;90:704-708.

32. Gnant MFX, Mlineritsch, B, Luschin-Ebengreuth G, et al. Zoledronic acid prevents cancer treatment-induced bone loss in premenopausal women receiving adjuvant endrocrine therapy for hormone-responsive breast cancer: a report from the Austrian Breast and Colorectal Cancer Study Group. J Clin Oncol. 2007;25(7):820-828.

33. Fouque-Aubert A, Chapurlat R. Influence of RANKL inhibition on immune system in the treatment of bone diseases. Joint Bone Spine. 2008;75:5-10

34. McClung MR, Lewiecki EM, Cohen ST, et al. Denosumab in postmenopausal women with low bone mineral density. $N$ Engl J Med. 2006;354(8):821-831.

35. Lipton A, Steger GG, Figueroa J, et al. Randomized active-controlled phase II study of denosumab efficacy and safety in patients with breast cancer-related bone metastases. J Clin Oncol. 2007 ; 25(28):4431-4437.

36. Body JJ, Facon T, Coleman RE, et al. A study of the biological receptor activator of nuclear factor- $k \mathrm{~B}$ ligand inhibitor, denosumab, in patients with multiple myeloma or bone metastases from breast cancer. Clin Cancer Res. 2006;12(4):1221-1228.

37. Fizazi K, Lipton A, Mariette X, et al. Randomized phase II trial of denosumab in patients with bone metastases from prostate cancer, breast cancer, or other neoplasms after intravenous bisphosphonates. J Clin Oncol. 2009;27(10):1564-1571.

38. Ellis GK, Bone HG, Chlebowski R, et al. Randomized trial of denosumab in patients receiving adjuvant aromatase inhibitors for nonmetastatic breast cancer. J Clin Oncol. 2008;26(30):4875-4882.

39. Watts NB, Cooper C, Lindsay R, et al. Relationship between changes in bone mineral density and vertebral fracture risk associated with risedronate: greater increases in bone mineral density do not relate to greater decreases in fracture risk. J Clin Densitom. 2004;7(3):255-261.
Breast Cancer: Targets and Therapy

\section{Publish your work in this journal}

Breast Cancer: Targets and Therapy is an international, peerreviewed open access journal focusing on breast cancer research, identification of therapeutic targets and the optimal use of preventative and integrated treatment interventions to achieve improved outcomes, enhanced survival and quality of life for the cancer patient.

\section{Dovepress}

View the full aims and scopes of this journal here. The manuscript management system is completely online and includes a very quick and fair peer-review system, which is all easy to use. Visit http:// www.dovepress.com/testimonials.php to read real quotes from published authors. 